\title{
De los filosofastros al philosophe. La melancolía del sabio y el sacerdocio del hombre de letras
}

\section{From philosophasters to the philosophe. The melancholy of learned men and the priesthood of men of letters}

\author{
Víctor CASEs MaRTínez \\ Universidad de Murcia \\ vcases@um.es
}

Fecha de recepción: 04-12-2017

Fecha de aceptación: 15-04-2018

\begin{abstract}
RESUMEN
Este artículo propone un recorrido a través de la figura del pensador de la Baja Edad Media a la llustración. Publicada en 1621, la Anatomía de la melancolía de Robert Burton dibuja la imagen del filósofo nuevo, opuesto a los desvergonzados filosofastros que daban título a la comedia de 1615. Demócrito Júnior supone la confirmación de la nueva figura intelectual que ha dejado atrás al clerc de la Baja Edad Media: el humanista del Renacimiento que, gracias a la rehabilitación llevada a cabo por Marsilio Ficino del mal de la bilis negra, confiesa con orgullo su carácter melancólico, propio del genio fuera de lo común. Su sucesor, el philosophe del siglo XVIII ya no necesita acudir a la afección atrabiliaria para postularse como el guía que ha de conducir y domesticar al pueblo.
\end{abstract}

PALABRAS CLAVE: melancolía, filosofastros, época moderna, philosophe, pueblo.

ABSTRACT

This article proposes a journey through the figure of the thinker from the late Middle Ages to the Enlightenment. Published in 1621, Robert Burton's Anatomy of Melancholy depicts the image of the new philosopher as opposed to those shameless philosophasters, to which the title of his 1615 comedy refers. Democritus Junior embodies the confirmation of the new intellectual figure that has abandoned the clerc of the late Middle Ages: that Renaissance humanist who, thanks to Marsilio Ficino's rehabilitation of the malady of the black bile, proudly confesses his melancholic character, typical of extraordinary geniuses. His successor, the 18th century philosophe, no longer needs to resort to bad-tempered humour in order to present himself as the guide destined to direct and domesticate common people.

KEY WORDS: melancholy, philosophasters, early modern period, philosophe, common people. 


\section{INTRODUCCIÓN}

"De todas las naciones de Europa Francia era, desde hacía ya tiempo, la más literaria; no obstante, los hombres de letras jamás habían revelado un espíritu como el que mostraron hacia mediados del siglo XVIII, ni ocupado una posición como la alcanzada entonces. Algo así, nunca antes se había visto entre nosotros, ni creo que en ningún otro lugar".

El entrecomillado pertenece al primer capítulo del libro III de L'Ancien Régime et la Révolution, el clásico estudio publicado por Alexis de Tocqueville en 1856. El título de dicho capítulo no puede ser más elocuente: "Cómo, hacia mediados del siglo XVIII, los hombres de letras se convirtieron en los principales hombres políticos del país, y de los efectos derivados de ello".

Las tesis de Tocqueville convocan no pocos problemas. Acaso para nuestro propósito los que resultan más relevantes son los que tienen que ver con la difusión de las nuevas teorías, que alumbradas por los hombres de letras según el autor francés descendían en la escala social hasta límites insospechados, hasta excitar la fantasía de mujeres y campesinos $^{2}$. El argumento es muy discutible desde el punto de vista histórico y es inadmisible desde el punto de vista historiográfico y sociológico. Daniel Mornet emplea un razonamiento similar en Les origines intellectuelles de la Révolution française ${ }^{3}$, un método que según Robert Darnton toma la forma de "una especie de cafetera francesa", en la que las ideas filosóficas alojadas en las altas esferas bajan hasta el pueblo y desde aquí impulsan el espíritu revolucionario ${ }^{4}$. Como advierte Roger Chartier, la operación de Mornet se sostiene a partir de una premisa errónea, según la cual las ideas no sufren ninguna transformación durante los complicados procesos de apropiación y reapropiación a los que están sometidas 5 .

Dicha premisa traduce además una mirada despectiva hacia el pueblo llano (capaz tan sólo de reproducir sin más las verdades proferidas por el selecto grupo de philosophes que trazan la senda del progreso), la cual como veremos es uno de los rasgos estructurales del intelectual, que se adivina tras la melancolía del sabio dibujado por Robert Burton y adquiere una presencia soberbia en los discursos de aquellos hombres de letras de mediados del siglo XVIII que tuvieron un papel tan destacado según Tocqueville.

Con todo, la intuición de este constituye, a nuestro juicio, un atractivo punto de partida, pues plantea en pocas palabras una de las cuestiones a las que trataremos de responder en estas páginas. Según Tocqueville, lo que caracterizaba a los escritores franceses de las últimas décadas del Antiguo Régimen era una "suerte de política abstracta y literaria6" que logró transformar la rabiosa y penosa actualidad de la época en un mundo imaginario, en un universo teórico capaz de devolver la ilusión a una población hastiada. Desde nuestra perspectiva, la ascendencia social de Voltaire y compañía tiene que ver antes que nada con

1 A. de Tocqueville, El Antiguo Régimen y la Revolución, Madrid, Istmo, 2004, edición de Antonio Hermosa Andújar, p. 191.

2 Ibíd., pp. 192-193.

3 D. Mornet, Les origines intellectuelles de la Révolution française: 1715-1787, Paris, Armand Colin, 1933 (traducción española: Los orígenes intelectuales de la Revolución Francesa, 1715-1787, Buenos Aires, Paidós, 1969, traducción de Carlos A. Fayard).

4 R. Darnton, Los best sellers prohibidos en Francia antes de la Revolución, Buenos Aires, FCE, 2008, traducción de Antonio Saborit, p. 257.

5 R. Chartier, Espacio público, crítica y desacralización en el siglo XVIII. Los orígenes culturales de la Revolución Francesa, Barcelona, Gedisa, 2003, traducción de Beatriz Lonné, pp. 31-32.

6 A. de Tocqueville, El Antiguo Régimen y la Revolución, p. 192. 
la construcción histórica de un personaje que, tras desvincularse del resto de los mortales, reclamó para sí el lugar más elevado del púlpito para impartir su sacerdocio.

Como sugiere Jean-Marie Goulemot, el genio que asoma bajo el hombre de letras de mediados del siglo XVIII "representa la forma laica del inspirado de tiempos anteriores". Para esbozar su fisonomía parece aconsejable, por tanto, trazar una historia de larga duración, que en este caso transitará por otras figuras intelectuales (antes de llegar al philosophe): el magister, el dominus y el humanista, los dos primeros pertenecientes a la Baja Edad Media y el último al Renacimiento.

Proponemos así un recorrido articulado en torno a tres epígrafes: el título del primero de ellos, Philosophastri, remite a una comedia de Robert Burton estrenada en 1617 y a los desvergonzados individuos instalados en las decadentes universidades renacentistas; frente a ellos, en el segundo apartado encontramos al filósofo nuevo perfilado por el mismo autor en su obra de 1621, cuya atenta lectura nos ofrece la posibilidad de resumir la dilatada historia de sus antecesores -los intelectuales medievales- y nos permite comprender asimismo cómo la rehabilitación de la melancolía llevada a cabo por Marsilio Ficino supuso una espléndida oportunidad para el sabio apartado del mundo, para el humanista del Renacimiento que compartía de este modo con los hombres excepcionales de todos los tiempos su peculiar afección atrabiliaria; por último, analizamos la figura del philosophe que toma cuerpo en el París de la Encyclopédie, quien, frente a la multitud ciega, cumple en la sociedad -según Jean-Jacques Garnier- la función de los ojos en el cuerpo humano ${ }^{8}$, quien aporta la luz, la metáfora por excelencia del siglo que fue testigo del movimiento ilustrado.

\section{PHILOSOPHASTRI}

Nacido bajo el signo de Saturno, el filósofo es de natural melancólico por más que se empeñe en combatir las causas de su inevitable melancolía, como pretendía Democritus Junior, el seudónimo del que se sirvió Robert Burton para firmar su obra publicada en $1621^{9}$. Como apunta Wolf Lepenies ${ }^{10}$, el nombre del huraño filósofo griego era casi de obligada referencia en la época al tratar el tema del mal de la bilis negra: así, por ejemplo, el Democritus, or Doctor Merry Man, His Medicine Against Melancholy Humours de Samuel Rowlands que vio la luz en 1607, o el Democritus ridens, sive campus recreationum honestarum cum exorcismo melancholiae, publicado por Johann Peter Lange en 1649. Se trataba de un lugar común que no podía dejar de conocer Robert Burton, un "clérigo y anacoreta universitario, que pasó su vida en las bibliotecas y bebió de todas las ciencias, tan erudito como Rabelais, de una memoria inagotable y desbordante ${ }^{11 "}$, que se presenta

7 J.-M. Goulemot, Adieu les philosophes: que reste-t-il des Lumières?, Paris, Seuil, 2001, p. 80 : "Représente la forme laïque de l'inspiré des temps antérieurs".

8 J.-J. Garnier, L'Homme de lettres, Paris, Panckoucke, 1764, p. 144.

9 R. Burton, Anatomía de la melancolía, Madrid, Asociación Española de Neuropsiquiatría, 1997-2002, 3 vols., prefacio de Jean Starobinski, traducción de Ana Sáez Hidalgo, Raquel Álvarez Peláez y Cristina Corredor. Tras su aparición en 1621, la obra conoció cuatro reediciones corregidas y aumentadas progresivamente por el autor, en 1624, 1628, 1632 y 1638. La Anatomía de la melancolía fue impresa de nuevo en 1651. La traducción de la Asociación Española de Neuropsiquiatría ha tomado como referencia el texto de 1632, ya que lo considera más fiable y limpio de erratas que la edición de 1651.

10 W. Lepenies, ¿Qué es un intelectual europeo? Los intelectuales y la política del espíritu en la historia europea, Barcelona, Galaxia Gutenberg/Círculo de Lectores, 2008, traducción de Sergio Pawlosky. Lepenies dedica a Robert Burton el primer apartado de su segunda lección (que como las demás fueron leídas en el Collège de France en 1992), "Pensamiento utópico y melancolía", pp. 40-77.

11 Así comienza la semblanza que sobre Robert Burton realizó Hippolyte Taine en su Histoire de la littérature anglaise, dentro del capítulo dedicado al "Renacimiento pagano": "Robert Burton, ecclésiastique et solitaire 
a sí mismo como un estudioso apartado del mundo, donde ha disfrutado de "una vida tranquila, sedentaria, solitaria, apartada, a solas con las musas ${ }^{12 " .}$.

Como señala Eugenio Garin ${ }^{13}$, la imagen del filósofo que se dibuja a través de las numerosas páginas de Burton, que brota de las infinitas referencias a la luz de las cuales Democritus Junior nos allana el camino de la intrincada melancolía es, en definitiva, la del filósofo nuevo, que se opone a todos aquellos philosophastri que daban título a la comedia compuesta por el erudito inglés en 1606 (aunque fue en 1615 cuando completó la versión definitiva $)^{14}$. En ella se cuentan las peripecias de un nutrido grupo de estudiantes que, venidos de toda Europa, acudieron a la llamada de Desiderius, el duque de Osuna, quien ofrecía a los alumnos que formaran parte de su recién fundada universidad "no sólo las ventajas de la escuela, sino salarios y tantas cosas como fuera preciso ${ }^{15}$ ". En respuesta a la invitación -leemos en el argumento de la obra-, junto con alcahuetas y prostitutas, llegaron filósofos de todas partes y entre ellos también filosofastros, que eran preferidos antes que todos los demás ${ }^{16}$.

Seguros de sí mismos, los filosofastros no derrocharon demasiados esfuerzos para preparar su ingreso en la escuela. Así, Polupragmaticus, que se presenta como un destacado gramático, retórico, geómetra, pintor, luchador, adivino, funámbulo, físico, mago ("en una palabra, un Jesuita ${ }^{17 ")}$, que preguntado por Eubulus -miembro del consejo del duque- se declara capaz de responder a cualquier cuestión sobre teología, filosofía, medicina, estadística, estenografía o quiromancia, y además se hace acompañar por un sirviente llamado Equivocus, le proporciona a Ludovicus Pantometer -un matemático que abusa con sus astutos trucos del pueblo llano- la receta infalible para ser aceptado en la universidad: "Toma este libro y aprende por el camino algunas palabras largas ${ }^{18 "}$ ". Algo de lo que ni siquiera se preocupó el poetastro Amphimacer, que llegó a la entrevista del día de la admisión completamente ebrio, o, como prefiere llamarlo Polupragmaticus, "movido por una suerte de inspiración ${ }^{19 " .}$.

Los filosofastros camparon a sus anchas hasta que recibieron finalmente su merecido. Debido a sus continuos atropellos (Polupistos, por ejemplo, un noble de la comarca, se vio burlado tanto por Polupragmaticus como por Pantomagus, un alquimista que como Ludovicus Pantometer gustaba de engañar además a la multitud), llegaron numerosas quejas al duque de Osuna, quien amenazó con el exilio a los estudiantes y con el cierre de la universidad, lo que no sucedió gracias a la intervención de Polumathes y Philobiblos, dos eruditos errantes que ejercerán de administradores de la escuela. Siguiendo su consejo, el duque convocó un tribunal extraordinario ante el que comparecieron los filosofastros, la alcahueta y sus dos hijas. Todos ellos fueron duramente castigados, el ambiente se apaciguó y se establecieron nuevos decretos que velaran por el correcto funcionamiento de la institución.

d'Université, qui passa sa vie dans les bibliothèques et feuilleta toutes les sciences, aussi érudit que Rabelais, d'une mémoire inépuisable et débordante". H.- A. Taine, Histoire de la littérature anglaise, Paris, L. Hachette, $2^{\mathrm{e}}$ édition revue et augmentée, vol. I, 1866, p. 374.

12 R. Burton, Anatomía de la melancolía, vol. I, p. 42.

13 Véase E. Garin, "El filósofo y el mago", en E. Garin (ed.), El hombre del Renacimiento, Madrid, Alianza, 1990, traducción de Manuel Rivero Rodríguez, pp. 66-68.

14 R. Burton, Philosophaster, Whitefish, Kessinger Publishing, 1992, ed. Latin-English.

15 Ibíd. p. 4: "Non tam privilegiis, sed et salario se digno, caterisque necesariis".

16 Ibíd.

17 Ibíd., p. 32: "Vel si mavis Jesuita, ut dicam semel".

18 Ibíd., p. 24: "Librum hunc cape, / Edisce hinc verba quaedem sesquipedalia".

19 Ibíd., p. 38: "Non, sed enthusiasmo quodam percitus". 
El nuevo Demócrito que intenta diseccionar la dolorosa melancolía no tiene nada que ver, como afirmábamos más arriba, con todos esos filosofastros, aquellos "asnos que llenaban las escuelas -subraya Eugenio Garin-, ahora ya con el único deber de poner en circulación otros asnos ${ }^{20 "}$.

\section{EL NUEVO DEMÓCRITO. DEL MAGISTER MEDIEVAL AL HUMANISTA DEL RENACIMIENTO}

En el fondo, la renovada imagen del filósofo que se percibe a través de la distancia entre las dos obras de Robert Burton es la confirmación de la nueva figura intelectual que se viene gestando desde el Renacimiento: el humanista que ha dejado atrás al insigne maestro universitario, al intelectual medieval dibujado por Jacques Le Goff ${ }^{21}$.

Este último nació con la revolución urbana que se advierte ya en el siglo $X$ y cristaliza finalmente en el siglo XII según el historiador francés. Aparece por tanto con la eclosión de las ciudades en las que se impone la división del trabajo como un nuevo tipo socioprofesional, un hombre de oficio cuya tarea es pensar y difundir sus pensamientos en el nuevo espacio que le es destinado, que no son las escuelas monásticas restringidas a los futuros monjes, sino las escuelas urbanas en principio abiertas a todos. "Este tipo -concluye Le Goff- se anuncia en la Alta Edad Media, se desarrolla en las escuelas urbanas del siglo XII y florece a partir del siglo XIII en las universidades ${ }^{22 ", ~ q u e ~ c u e n t a n ~ c o n ~ u n ~ s i s t e m a ~ d e ~ p r o m o c i o ́ n ~}$ social inédito en Occidente, el examen, el cual permite la entrada de cierto número de estudiantes procedentes de familias más humildes.

Es este personaje, el clerc representado en la danza macabra de finales de la Edad Media (figura 1), con sus gruesas lentes -un objeto de lujo propio sólo de quienes contaban con una desahogada posición económica- como síntoma inequívoco de su persistente y fatigoso estudio (figura 2), el que tenderá a desaparecer a partir de los últimos decenios del siglo XIV, en un declive lento y prolongado que aún dará lugar a las críticas de Burton, entre otros, contra el escolasticismo esclerotizado a comienzos del XVII. Doscientos años antes las universidades ya muestran signos de agotamiento. Aquella corriente de estudiantes de condición modesta que había impulsado el desarrollo de las facultades se ve reducida a su mínima expresión, los estatutos universitarios recortan sobremanera el cupo de alumnos que reciben instrucción gratuita y con frecuencia los ingresos procedentes de las becas son mantenidos en una tasa fija que asume con extrema dificultad el galopante encarecimiento de la vida. Las universidades no podían quedar al margen de la profunda crisis que sacude la Europa occidental de finales de la Edad Media -azotada por el hambre, las pestes, las numerosas guerras-, que impulsa a los universitarios hacia los nuevos centros de riqueza, la corte del príncipe y los acaudalados mecenas.

Además, la renovación del personal docente se detiene debido a la "aristocratización de la universidad ${ }^{23}$ ", cuyos miembros en algunos casos se suceden de manera hereditaria ${ }^{24}$ -Le Goff cita a este respecto los estatutos de Bolonia y Padua aprobados a finales del

20 E. Garin, "El filósofo y el mago", p. 168.

21 J. Le Goff, Los intelectuales en la Edad Media, Barcelona, Gedisa, 1986, traducción de Alberto L. Bixio.

22 Ibíd., p. 21.

23 Ibíd., p. 122.

24 Podemos mencionar el ejemplo de Novella d'Andrea, que en el siglo XIV cuando falleció su padre ocupó el puesto que este desempeñaba, profesor de Derecho Canónico en la Universidad de Bolonia. La sucesión hereditaria de los docentes universitarios llega a tal extremo que en ocasiones logra sobrepasar las barreras de género. Véase L. Schiebinger, Nature's body. Gender in the Making of Modern Science, New Brunswick (New Jersey), Rutgers University Press, 2006, p. 190, nota 23). 
siglo XIV-, adoptan un alto tren de vida (su ostentosa vestimenta, sus lujosas casas o sus soberbios féretros dan buena muestra de ello) y observan escrupulosamente no pocos rituales que los aproximan a la nobleza, como la cada vez mayor cantidad de guantes que han de regalar los estudiantes candidatos a los profesores en el momento del examen o las fastuosas fiestas que se celebran con motivo de la investidura de un nuevo doctor, que a menudo se ve acompañada por representaciones teatrales, bailes o torneos que se asemejan a los organizados por la encopetada alcurnia. El humilde magister se convierte en dominus, el título que antes identificaba al conductor del taller urbano es ahora signo de eminente distinción, de gloria (es sin duda muy significativo el hecho de que en 1533 Francisco I otorgue la caballería a los doctores de la universidad), una dignidad que suele ir acompañada de un profundo desprecio hacia el trabajo manual.

Si el dominus trastoca profundamente el significado de su antecesor, con la consagración del humanista apenas quedará rastro de aquel maestro universitario que emergió en las escuelas urbanas del siglo XII. La nueva figura intelectual ya no quedará definida en virtud de esa doble tarea que caracterizaba al clerc, quien además de fijar sus lentes en la concienzuda lectura de los textos filosóficos se entregaba de lleno a la enseñanza en mitad de un auditorio que no estaba compuesto únicamente por iniciados. El humanista abandonará esta docencia. Su medio ya no será el taller urbano, sino la corte del príncipe; sus pensamientos ya no han de fluir -sostiene Erasmo al comienzo de El banquete religioso- junto a la multitud que abarrota "las humosas e ahogadas cibdades ${ }^{25}$ ", sino en el campo, a salvo del pueblo, de "los ciegos" y sus "ganancias"26". Colmado de libros en la apacible soledad de su gabinete, el ennoblecido humanista -como tampoco lo hará el philosophe- ya no alzará su voz en las gélidas aulas universitarias que contemplaban el derecho al pataleo, sino en las instituciones más selectas de la oligarquía intelectual, los colegios -que según Le Goff "cristalizaron la aristocratización de las universidades 27"-, entre ellos el insigne Collège des Lecteurs Royaux (el futuro Collège de France) fundado por Francisco I en 1530, o las academias que vieron la luz en la Italia renacentista antes de propagarse por toda Europa, que en palabras de Voltaire "son a la universidad lo que la edad madura es a la infancia, lo que el arte de hablar bien es a la gramática, lo que la politesse es a las primeras lecciones de civilidad ${ }^{28 "}$.

Uno de aquellos centros preferidos por los humanistas albergó a Robert Burton, quien al comienzo de su Anatomía de la melancolía se jacta de haber sido "estudiante del colegio más ilustre de Europa"29", el Christ Church College de Oxford, donde la comedia de los filosofastros fue representada por vez primera por los propios alumnos del colegio el 16 de febrero de 1617.

Nueve años más tarde, su autor fue nombrado bibliotecario de la institución, un cargo que satisfacía por completo a aquel "nuevo Demócrito", que a buen seguro se asemejaba

25 Erasmo de Rotterdam, "Colloquio llamado Combite religioso", en A. Herrán y M. Santos (eds.), Coloquios familiares: edición de Alonso Ruiz de Virués (siglo XVI), Rubí (Barcelona), Anthropos, 2005, p. 89.

26 Ibíd., p. 90: "Vayan a la buena ventura los ciegos con su ganancia -dice Eusebio a Timoteo-; nosotros somos filósofos".

27 J. Le Goff, Los intelectuales en la Edad Media, p. 122.

28 "Les académies sont aux universités c'est que l'âge mûr est à l'enfance, ce que l'art de bien parler est à la grammaire, ce que la politesse est aux premières leçons de civilité" (Voltaire, "Académie", en Euvres complètes de Voltaire, Paris, Garnier frères, 1877-1885, nouvelle édition, avec notices, préfaces, variantes, table analytique, les notes de tous les commentateurs et des notes nouvelles, conforme pour le texte à l'édition de Beuchot, enrichie des découvertes les plus récentes et mise au courant des travaux qui ont paru jusqu'à ce jour, vol. XVII. Dictionnaire philosophique, tome I, 1878, pp. 50-51).

29 R. Burton, Anatomía de la melancolía, vol. I, p. 42. 
bastante al antiguo sabio griego, de quien Hipócrates y Diógenes Laercio contaban que "era un hombrecillo anciano y fatigoso, muy melancólico por naturaleza, receloso de compañía en sus últimos días y muy dado a la soledad $30 "$. En su voluminosa obra de 1621, Demócrito Júnior se propone la esforzada tarea de proseguir y terminar el libro que según el relato de Hipócrates (su Epístola a Damageto) el filósofo de Abdera dejó inacabado y ahora está perdido $^{31}$, un importante tratado acerca de la atrabilis o bilis negra, una de las sustancias básicas que componen el cuerpo humano según la teoría hipocrática de los cuatro humores (contamos además con la bilis amarilla, la sangre y la flema), de cuyo equilibrio depende el estado de salud de la persona. Nacidos bajo el influjo telúrico de Saturno ${ }^{32}$, aquellos que padecen un exceso de bilis negra son inevitablemente melancólicos -"escribo sobre la melancolía, confiesa Burton en el prólogo de la obra, para estar ocupado en la manera de evitar la melancolía ${ }^{33 "-}$, esto es, erráticos, somnolientos, meditabundos. La tradición no trató demasiado bien a quienes así se hallan constituidos. Estos soportaron las representaciones medievales según las cuales la melancolía era sinónimo de acedia, pereza, y por lo tanto un vicio, la antesala del pecado, hasta la rehabilitación renacentista de la melancolía ${ }^{34}$ llevada a cabo ante todo por Marsilio Ficino al rescatar el sugestivo Problemata XXX atribuido a Aristóteles, que lanzaba una pregunta que iba a abrir las puertas a una consideración muy diferente de la afección atrabiliaria:

¿Por qué razón todos aquellos que han sido hombres de excepción, bien en lo que respecta a la filosofía, o bien a la ciencia del Estado, la poesía o las artes, resultan ser claramente melancólicos, y algunos hasta el punto de hallarse atrapados por las enfermedades provocadas por la bilis negra, tal y como explican, de entre los relatos de tema heroico, aquellos dedicados a Heracles? ${ }^{35}$.

La respuesta del estagirita no deja lugar a dudas: la melancolía no es una aflicción pasajera, sino el rasgo estructural por antonomasia de los individuos dotados de una determinada constitución. La naturaleza atrabiliaria no deja de suponer una peligrosa tendencia hacia numerosas enfermedades, entre ellas la completa enajenación mental (como según Aristóteles le sucedió a Áyax ${ }^{36}$ ); sin embargo, la recuperación por parte del neoplatonismo renacentista del texto aristotélico dota a la melancolía de una ambivalencia que se halla lejos de la iconografía medieval: además de una inagotable fuente de

\section{Ibíd.}

31 Ibíd., p. 45.

32 Ibíd., 43: "Saturno fue el planeta de mi nacimiento -confiesa Demócrito júnior-, y Marte el planeta que gobierna mis costumbres".

33 Ibíd., p. 45.

34 Según Giorgio Agamben, en la Edad Media se conocía la doble dimensión (presente desde la patrística antigua) de la acedia, que no sólo contenía una importante carga negativa, sino también un valor positivo que facilitó la lectura renacentista del desorden melancólico (G. Agamben, Stanze. La parola e il fantasma nella cultura occidentale, Torino, Einaudi, 1977). Roger Bartra recuerda a este respecto la dualidad que posee la tristeza o tristitia (estrechamente vinculada a la acedia) en las palabras que Pablo de Tarso dirigió a los corintios, según las cuales la tristeza es capaz de provocar la muerte, pero puede ayudar asimismo a lograr la salvación mediante el firme y sincero arrepentimiento (R. Bartra, Cultura y melancolía. Las enfermedades del alma en la España del Siglo de Oro, Barcelona, Anagrama, 2001, p. 157).

35 Aristóteles, El hombre de genio y la melancolía: problema XXX, I, Barcelona, Quaderns Crema, 1996, edición bilingüe, prólogo y notas de Jackie Pigeaud, traducción de Cristina Serna, p. 79.

36 Ibíd., pp. 79-81: "Por no hablar ya de lo que concierne a Áyax y aun a Belofonte -afirma Aristóteles-; el primero se tornó totalmente loco, el otro vagaba en busca de lugares solitarios". 
desórdenes físicos y espirituales, o tal vez por eso mismo, porque bordea el abismo de la locura y la muerte (aquella calavera sobre la que reflexiona la protagonista del lienzo de Domenico Fetti; figura 3), la melancolía es el germen de la creatividad, la sustancia del genio. Así queda reflejado en la famosa Melencolia I de Albrecht Dürer, el grabado de 1514 que el propio Robert Burton no puede dejar de mencionar (figura 4): en él aparece en primer plano Melancolía, que está sentada sobre un banco de piedra, la mejilla apoyada sobre el puño izquierdo, mientras con la mano derecha sujeta mecánicamente un compás que descansa sobre un libro cerrado. Coronada con verbena, la flor que ahuyenta la locura, la acompañan un querubín y un perro dormido a sus pies, acaso, como señala Panofski, el complemento preciso de la protagonista del grabado, cuya inactividad consciente contrasta con la actividad inconsciente del angelito y la inactividad inconsciente del animal ${ }^{37}$. Los tres se encuentran cerca del mar, en mitad de una fría noche -que adivinamos gracias al arco iris lunar- junto a un edificio inacabado. Si observamos la escena con detenimiento comprendemos el porqué de esta construcción inconclusa. Melancolía está absorta, con la mirada perdida en el vacío. Es una figura alada, símbolo de la imaginación y la creatividad que caracterizan al genio fuera de lo común, que sin embargo en ningún momento da la sensación de que pueda emprender el vuelo. Esparcidos por el suelo una serie de objetos desordenados, un tintero, una pluma, una escuadra, una esfera, un poliedro, los instrumentos del geómetra que ha suspendido su tarea -tal es el significado de la escalera apoyada contra el muro-, que abismado en sus pensamientos no logra encontrar el sentido de un trabajo cuya finalización se resiste al paso del tiempo, como le recuerda el reloj de arena colocado sobre la pared. La inquietante sombra de Saturno planea sobre la escena bajo la forma de un cometa que surca el cielo, un fenómeno maléfico según las creencias de la época ${ }^{38}$ contra el que es preciso protegerse, por ejemplo, con el cuadro mágico que se encuentra junto al reloj de arena y se conoce con el nombre de la mesa de Júpiter, una tablilla basada en el número 4 y cuyas cifras leídas en cualquier sentido suman 34 .

Incapaz de vencerse a sí misma, quizá la figura central del grabado se deja llevar en sus ensoñaciones hacia un paraíso lejano, de la misma manera que Robert Burton -que además de considerar la afección atrabiliaria como una seña de identidad de determinados individuos la eleva a la categoría de elemento del cosmos, del que nada ni nadie se salva-, al constatar la imposibilidad de derrotar a la melancolía, decide construir "una Utopía propia, una Nueva Atlantis, una república poética mía propia, en la que pueda dominar libremente ${ }^{39 " . ~}$ Una eterna primavera -la antítesis del otoño, la estación saturnina por antonomasia- en la que no hay lugar ni tiempo para la ociosidad, la "mayor causa de melancolía"0", pues además de contar con una precisa distribución de los espacios (una descripción detallada del emplazamiento y la función de las iglesias, las prisiones, los hospitales, las escuelas, los mercados) y una rigurosa delimitación de las leyes cuya inobservancia merece un severo castigo, contiene una pormenorizada planificación de las actividades humanas. La

37 R. Klibansky, E. Panofsky y F. Saxl, Saturno y la melancolía. Estudios de historia de la filosofía de la naturaleza, la religión y el arte, Madrid, Alianza, 1991, versión española de María Luisa Balseiro, pp. 309310. Sobre este y otros grabados del artista de Nüremberg, véase A. Rivera García, "La pintura de la crisis: Albrecht Dürer y la Reforma", Artificium. Revista iberoamericana de estudios culturales y análisis conceptual, 1 (2010), pp. 100-119.

38 En 1456 el papa Calixto III excomulgó al cometa Halley al considerarlo un emisario del mal.

39 R. Burton, Anatomía de la melancolía, vol. I, p. 107. Sobre el proyecto utópico de Burton, véase el prefacio de J. Starobinski, "Habla Demócrito. La utopía melancólica de Robert Burton", en R. Burton, Anatomía de la melancolía, vol. I, traducción de Julián Mateo Ballorca, pp. 11-29 (en particular, pp. 23-29).

40 R. Burton, Anatomía de la melancolía, vol. I, p. 45. 
de Robert Burton comparte en definitiva con la práctica totalidad de las utopías modernas la obsesiva y minuciosa codificación de los preceptos y costumbres, del orden que ha de regir el territorio nuevo, acaso porque todas ellas, en mayor o menor medida, pretenden ser un antídoto eficaz contra el grave desorden melancólico.

\section{EL PHILOSOPHE}

Tal vez la figura alada de Dürer refleja sin más la esencia del mal de la bilis negra, la razón por la que el melancólico siente un profundo dolor por el mundo que lo rodea y por sí mismo: la incapacidad de abandonar el pensamiento para acometer la acción y la apesadumbrada conciencia de ello. Es una suerte de "sistema que actúa al revés", dirá Diderot en sus Éléments de physiologie:

Nada es más contrario a la naturaleza que la meditación habitual o la condición de savant. El hombre ha nacido para actuar; el verdadero movimiento del sistema no es reconducirse constantemente de sus extremidades al centro nervioso, sino dirigirse del centro a las extremidades de los nervios [...] El hombre de la naturaleza está hecho para pensar poco y actuar mucho; el hombre de ciencia, por el contrario, piensa mucho y se mueve poco ${ }^{41}$.

El enciclopedista francés está inmerso de lleno en un mundo para el que la vida contemplativa ha dejado de ser no ya un ideal, sino ni tan siquiera una opción fugazmente apetecible. Como sugiere Max Weber, la vida activa se convirtió en un modelo indiscutible con el arraigo de la ética protestante y las exigencias del espíritu capitalista ${ }^{42}$. El filósofo nacido bajo el signo de Saturno se torna sospechoso, el melancólico sumido en una intensa reflexión que le imposibilita finalizar su tarea parece la contrafigura de los nuevos tiempos. Con todo, se las arreglará para salir adelante y no de cualquier manera, pues su peor debilidad constituye a la vez el signo de su soberbia fortaleza.

Las palabras de Diderot no son una crítica al "hombre de ciencia", sino todo lo contrario: reflejan en el fondo el amargo deleite de quien está convencido de que su camino es mucho más pedregoso que el de la inmensa mayoría de los mortales (los "hombres de la naturaleza"), la dulce melancolía -como reza el título del cuadro pintado por Joseph-Marie Vien en 1758 (figura 5)- del savant cuyo fatum, cuyo extraordinario destino está ligado a su incorregible carácter (a su daimon, diría Heráclito), que lo acredita como uno de los depositarios del conocimiento, uno de los elegidos que reclaman para sí el monopolio de un saber inaccesible para la gente común: "El imperio de las ciencias y de las artes -afirma Diderot en el Prospectus del diccionario coeditado por él y d'Alembert- es un mundo alejado del vulgo ${ }^{43}$ ", que no

41 El citado fragmento aparece bajo el epígrafe "Système agissant à rebours": "C'est que rien n'est plus contraire à la nature que la méditation habituelle ou l'état de savant. L'homme est né pour agir ; le mouvement vrai du système n'est pas de se ramener constamment de ses extrémités au centre du faisceau, mais de se porter du centre aux extrémités des filets [...] L'homme de la nature est fait pour penser peu et agir beaucoup ; I'homme de la science, au contraire, pense beaucoup et se remue peu" (D. Diderot, "Éléments de physiologie", en FEuvres complètes de Diderot revues sur les éditions originales comprenant ce qui a été publié à diverses époques et les manuscrits inédits conservés à la Bibliothèque de lıErmitage, Paris, Garnier frères, 1875-1877, notices, notes, table analytique, étude sur Diderot et le mouvement philosophique au XVIIle siècle par Jules Assézat [et Maurice Tourneaux], vol. IX. Poésies diverses. Sciences, 1875, p. 273).

42 Véase M. Weber, La ética protestante y el "espíritu" del capitalismo, Madrid, Alianza, 2001, traducción de Joaquín Abellán García. Como es sabido, Weber encontró en concreto en el protestantismo ascético de raíz calvinista el fundamento de la mentalidad capitalista que tan bien sintetizan los textos de Benjamin Franklin que cita al comienzo del libro.

43 D. Diderot, "Prospectus" [de l'Encyclopédie ou Dictionnaire raisonné des sciences, des arts et des métiers], en d'Alembert, Discours préliminaire des éditeurs de 1751 et articles de l'Encyclopédie introduits par la querelle 
sólo queda así incapacitado para las actividades intelectuales y el placer estético, sino que aparece, además, como "una hidra de cien cabezas", leemos en el Dictionnaire universel de Furetière de $1690^{44}$, un monstruo desgobernado si es abandonado a su suerte, una fiera cuya única posibilidad pasa por ser sometida y guiada por los philosophes, que se presentan como los domadores de la bestia salvaje: "Nosotros -escribe Diderot a Necker el doce de junio de 1775- somos ese pequeño número de cabezas que, situadas en el cuello del gran animal, arrastran tras ellas a la multitud ciega de sus colas ${ }^{45 " .}$

Como sugiere Zygmunt Bauman a propósito de una distinción que se parece mucho a la establecida en los Éléments de physiologie, la propuesta por Paul Radin entre el "sacerdotepensador" (priest-thinker) y el lego (layman) -los "dos tipos generales de temperamento entre los pueblos primitivos ${ }^{46 "}$-, la profunda asimetría generada entre "el hombre de ciencia" y "el hombre de la naturaleza" remite al juego de dominación y dependencia del desarrollo histórico. En el estudio del antropólogo norteamericano, el sentimiento de inseguridad que atemoriza a la "gente común" (common people) no remite nunca, pues las competencias intelectuales que sirven al selecto grupo de "formuladores religiosos" (religious formulators) para combatir la impredecibilidad de los acontecimientos consiguen neutralizar algunos peligros en la medida en que generan nuevas amenazas, con lo cual el proceso se retroalimenta al infinito. Los sacerdotes refuerzan su autoridad al presentar sus habilidades como parte integrante de un conocimiento esotérico, inalcanzable para los irreflexivos hombres de acción. Como veíamos, los ilustrados operan del mismo modo, y pese a que soportan las críticas de los sectores más conservadores que no pueden concebir la pasión del saber desvinculada de la fe, articulan una retórica que no está exenta de connotaciones religiosas, pues se trata "de esa pequeña manada -escribe Diderot en 1766-, de esa iglesia invisible que escucha, que observa, que medita, que habla bajo y cuya voz predomina a la larga y forma la opinión general47".

"En parte hombre de letras, en parte hombre de mundo metido de cabeza en el uso de las letras para liberar al mundo de la superstición ${ }^{48 ", ~ e l ~ p h i l o s o p h e ~ c r i s t a l i z o ́ ~ e n ~ l a s ~ u ́ l t i m a s ~}$ décadas del Antiguo Régimen como un nuevo tipo ideal, una élite en torno a la cual tomó

avec le Journal de Trévoux, Paris, Honoré Champion, 1999, textes établis et présentés par Martine Groult, p. 25: "L'empire des sciences et des arts est un monde éloigné du vulgaire".

44 A. Furetière, "Hydre", en Dictionnaire universel, contenant généralement tous les mots françois tant vieux que modernes, et les termes de toutes les sciences et des arts..., Paris, France-expansion, 1972-reproduction de l'édition de La Haye et Rotterdam, A. et R. Leers, 1690, 3 tomes dans un volume, non paginé-, tome II, p. 1050 : "Le Peuple est une hydre à cent testes".

45 Carta de Denis Diderot a Jacques Necker, doce de junio de 1775, en D. Diderot, Fuvres complètes de Diderot..., vol. XX. Correspondance, tome III, 1877, lettre LXVIII, p. 70: "Nous sommes ce petit nombre de têtes qui, placées sur le cou du grand animal, traînent après elles la multitude aveugle de ses queues".

46 P. Radin, Primitive Religion. Its Nature and Origin, New York, The Viking Press, 1937, p. 14: "Two general types of temperament among primitive peoples". Véase Z. Bauman, Legisladores e intérpretes. Sobre la modernidad, la posmodernidad y los intelectuales, Buenos Aires, Universidad Nacional de Quilmes, 1997, traducción de Horacio Pons.

47 Carta de Denis Diderot a Étienne-Maurice Falconet, septiembre de 1766, en D. Diderot, Fuvres complètes de Diderot..., vol. XVIII. Correspondance, tome I, 1876, p. 158: "Quand je parle de la voix publique, il ne s'agit pas de cette cohue mêlée de gens de toute espèce qui va tumultueusement au parterre siffler un chef d'œuvre, élever la poussière du Salon et chercher sur le livret, si elle doit admirer ou blâmer. Je parle de ce petit troupeau, de cette église invisible qui écoute, qui regarde, qui médite, qui parle bas et dont la voix prédomine à la longue et forme l'opinion générale".

48 R. Darnton, "La dentadura postiza de George Washington", en El coloquio de los lectores. Ensayos sobre autores, manuscritos, editores y lectores, México, FCE, 2003, prólogo, selección y traducción de Antonio Saborit, p. 292. 
forma el movimiento ilustrado, que, como escribe Robert Darnton, si bien se diseminó a través de muchos lugares (Londres, Ámsterdam, Milán...), se definió como una causa en el París de la Encyclopédie. Dotados del distinguido talento de pensar por sí mismos y de la invencible razón, la cual según Dumarsais es al philosophe lo que la gracia al cristiano ${ }^{49}$, Diderot y compañía no dejan de cantar las excelencias de aquellos atributos -reflexividad, espíritu de observación, moral intachable- que los singularizan frente al pueblo. Este se halla "entre el hombre y la bestia", afirma Voltaire ${ }^{50}$, "es sin duda un animal imbécil que se deja guiar en las tinieblas", concluye d'Alembert ${ }^{51}$. Por supuesto, el enciclopedista es uno de los pocos elegidos que sostienen la linterna.

\section{CONCLUSIONES}

Como el melancólico de Burton, también "piensa mucho y se mueve poco" el philosophe del Siglo de las Luces, pese a lo cual hemos de advertir que este último no se identifica con la figura trazada por el nuevo Demócrito, pues, aunque ha abandonado la desvergonzada actitud de los filosofastros que poblaban la universidad del conde de Osuna, no puede permitirse el lujo de la soledad, ni tan siquiera debe contentarse con el aprecio que sus colegas le demuestran en aquellas academias tan alabadas por Voltaire, de cuya creación, según Élisabeth Badinter, data "el acta de nacimiento de los intelectuales ${ }^{52 " . ~}$

La implantación de estas sociedades estatales, que contemplaban generosas pensiones para aquellos que ocupaban sus asientos, instituyó una nueva élite, un cuerpo de eruditos tocado por el dedo de la gracia, que es en este caso el del rey, provisto de la dignidad que recae casi de inmediato sobre quienes pasean sus libros y memorias por los nuevos templos del saber, que dotan a los discursos nacidos bajo sus auspicios de la distinción que enaltece su figura.

Pero esta nueva élite no se afianzó como tal hasta bien entrado el siglo XVIII. De ahí que debamos matizar la afirmación de Badinter: más que constituir su acta de nacimiento, las academias fundadas en el siglo de Luis XIV son una condición de posibilidad del intelectual, que cristaliza finalmente en la Ilustración, cuando, según Tocqueville, los hombres de letras supieron aprovechar la única libertad que se había salvado del largo proceso de centralización administrativa emprendido por la Corona, la libertad de filosofar, se colaron por esta hendidura y "arrogándose la dirección de la opinión pública, se vieron en cierto momento ocupar el lugar de ordinario ocupado por los jefes de partido en los países libres 53 ".

Sin duda también cabría matizar, o atemperar cuando menos, el entusiasmo de Tocqueville, pero su afirmación, una vez más, nos coloca sobre una pista interesante, nos ayuda a dar con las últimas notas de nuestra interpretación. Lejos del mundanal ruido, el humanista del Renacimiento se desvincula de los indignos intereses del dominus nacido de

49 C. Ch. Dumarsais, "Le Philosophe", en Nouvelles libertés de penser, Amsterdam, Piget, 1743, p. 175.

50 Voltaire, Les œuvres complètes de Voltaire / The Complete Works of Voltaire, Genève/Toronto/Paris, Institut et Musée Voltaire/University of Toronto Press, edited by Theodore Besterman], tome 82, Notebooks (vol. 2), 1968, p. 534: "Le peuple est entre l'homme et la bête".

51 Carta de d'Alembert a Federico II de Prusia, 30 de noviembre de 1770, en d'Alembert, "Correspondance avec le roi de Prusse", en Fuvres de d>Alembert. Paris, A. Belin, vol. V, partie II, 1822, p. 305: "Le peuple est sans doute un animal imbécile qui se laisse conduire dans les ténèbres".

52 É. Badinter, Les passions intellectuelles, vol. I. Désirs de gloire (1735-1751), Paris, Fayard, 1999, p. 10 -traducción española: Las pasiones intelectuales, vol. I. Deseos de gloria (1735-1751), Buenos Aires, FCE, 2007, traducción de Alejandrina Falcón-: "L'acte de naissance des intellectuels date de la création des Académies".

53 Ibíd., pp. 194-195. 
la aristocratización de la universidad que acabó con el humilde magister medieval; al tiempo que, infatigable, se entrega a la ardua labor de concluir el tratado sobre la melancolía de Demócrito como un modo de subrayar su extraordinaria naturaleza, traspasada por una afección que lo separa del resto de individuos, incapaces de su genio y de su mirada.

Si el savant del siglo XVII salía de su gabinete para buscar en la academia el reconocimiento de sus pares, ante todo en las últimas décadas del Antiguo Régimen el philosophe sabe que su prestigio, que su poder se pone en juego en la arena pública, más allá de los muros de la institución ${ }^{54}$. No es casual que d'Alembert, uno de los philosophes por antonomasia, a partir de 1761 deje de publicar sus memorias científicas en los volúmenes de la Académie française -de la que será secretario perpetuo desde 1772- y las difunda a través de su propio editor, bajo la forma de Opuscules. El protegido de Voltaire comprendía sin ningún género de duda que su función casi mesiánica tenía lugar allí donde acontecía esa nueva autoridad a la que nadie podía sustraerse, ya era plenamente consciente de lo que el patriarca de Ferney le dirá en una carta fechada el 26 de diciembre de 1767: "Es la opinión la que gobierna el mundo y es usted el que ha de gobernar la opinión ${ }^{55 " .}$

Es entonces cuando aparece lo que, a pesar del anacronismo del término, puede llamarse con rigor intelligentsia ${ }^{56}$, una nueva clase social, la élite de los intelectuales ${ }^{57}, 0$, como diría d'Alembert, "la clase maldita de los philosophes ${ }^{58 ", ~ q u e, ~ a r m a d o s ~ d e ~ l a ~ d i s t i n c i o ́ n ~}$ académica, obtienen más allá de los muros de la institución una nueva legitimidad en virtud de su pretendido magisterio público, que se despliega justo cuando el debilitamiento de las prácticas y símbolos tradicionales (la desacralización o desencanto ante la monarquía ${ }^{59}$, la desestructuración de las creencias y hábitos religiosos ${ }^{60}$ ) libera un espacio donde cabe

54 A pesar de que resulta útil asociar los términos savant y philosophe a dos modelos de pensadores que se suceden cronológicamente, conviene advertir que en el siglo XVIII las dos palabras son usadas indistintamente hasta los años cincuenta, cuando el vocablo savant comienza a designar de manera más clara al especialista en una determinada disciplina científica, de lo cual escapa el philosophe, que, como afirma Didier Masseau, establece un tipo de relación con el saber "que confiere a quien la detenta una competencia que le permite intervenir espontáneamente en todos los dominios de la cultura" ["qui confère à son détenteur une compétence lui permettant spontanément d'intervenir dans tous les domaines de la culture"]. D. Masseau, L'invention de l'intellectuel dans l'Europe du XVIIIe siècle, Paris, Presses Universitaires de France, 1994, p. 12.

$55 \quad$ Carta de Voltaire a d'Alembert, 26 de diciembre de 1767, en Voltaire, Correspondance, éditée par Theodore Besterman, [Paris], Gallimard, notes de Besterman traduites et adaptées par Frédéric Deloffre, vol. IX, 1985, lettre 10463 [D 14623], p. 231: “C'est l'opinion qui gouverne le monde, et c'est à vous de gouverner l'opinion".

56 Véanse P. Vernière, "Naissance et statut de l'intelligentsia en France", in Ch. Mervaud et S. Menant (éd.), Le siècle de Voltaire: hommage à René Pomeau, Oxford, Voltaire Foundation, 1987, vol. II, pp. 933-941; É. Walter, "Sur l'intelligentsia des Lumières", Dix-huitième siècle, 5, 1973, pp. 173-201.

57 Conviene precisar que, si bien a lo largo de este artículo usamos el término intelectual en sentido amplio (lo cual nos permite referirnos a los intelectuales de la Edad Media, como reza el título de Jacques Le Goff), a nuestro parecer el primer intelectual propiamente dicho es el philosophe del siglo XVIII.

58 d'Alembert, "Réflexions sur l'état présent de la République des lettres pour l'article gens de lettres, écrites en 1760 et par conséquent relatives à cette époque", en Euvres et correspondances inédites (éditées par Charles Henry), Genève, Slatkine, 1967, p. 73: "La classe maudite des philosophes".

59 A mi juicio, un modo sugerente de desentrañar este argumento es el caso Damiens, quien en 1757 hirió de un navajazo a Luis XV. Frente a la respuesta oficial al frustrado atentado (que subraya la bondad del monarca y la locura del criminal), no son pocos los súbditos que lamentan la oportunidad perdida y hasta declaran que ellos mismos habrían corrido mejor suerte. Véase D. K. Van Kley, The Damiens Affair and the Unraveling of the Ancien Régime, 1750-1770, Princeton, Princeton University Press, 1984.

60 La espectacular caída del libro de religión (que constituía la mitad de la producción impresa en París a finales del siglo XVII, una tercera parte hacia 1720, una cuarta parte a principios de los años cincuenta y tan sólo la décima parte en la década de 1780), el considerable descenso de las ordenaciones sacerdotales, 
un nuevo guía espiritual, una de cuyas señas de identidad es el profundo desprecio que siente hacia la multitud iletrada, hacia todos aquellos que a su juicio están condenados a convertirse en sus fieles.

Figura 1. Danse macabre. Le clerc théologien, le laboureur et le cistercien, mediados del siglo XV (Abbaye de Saint-Victor, Marseille).

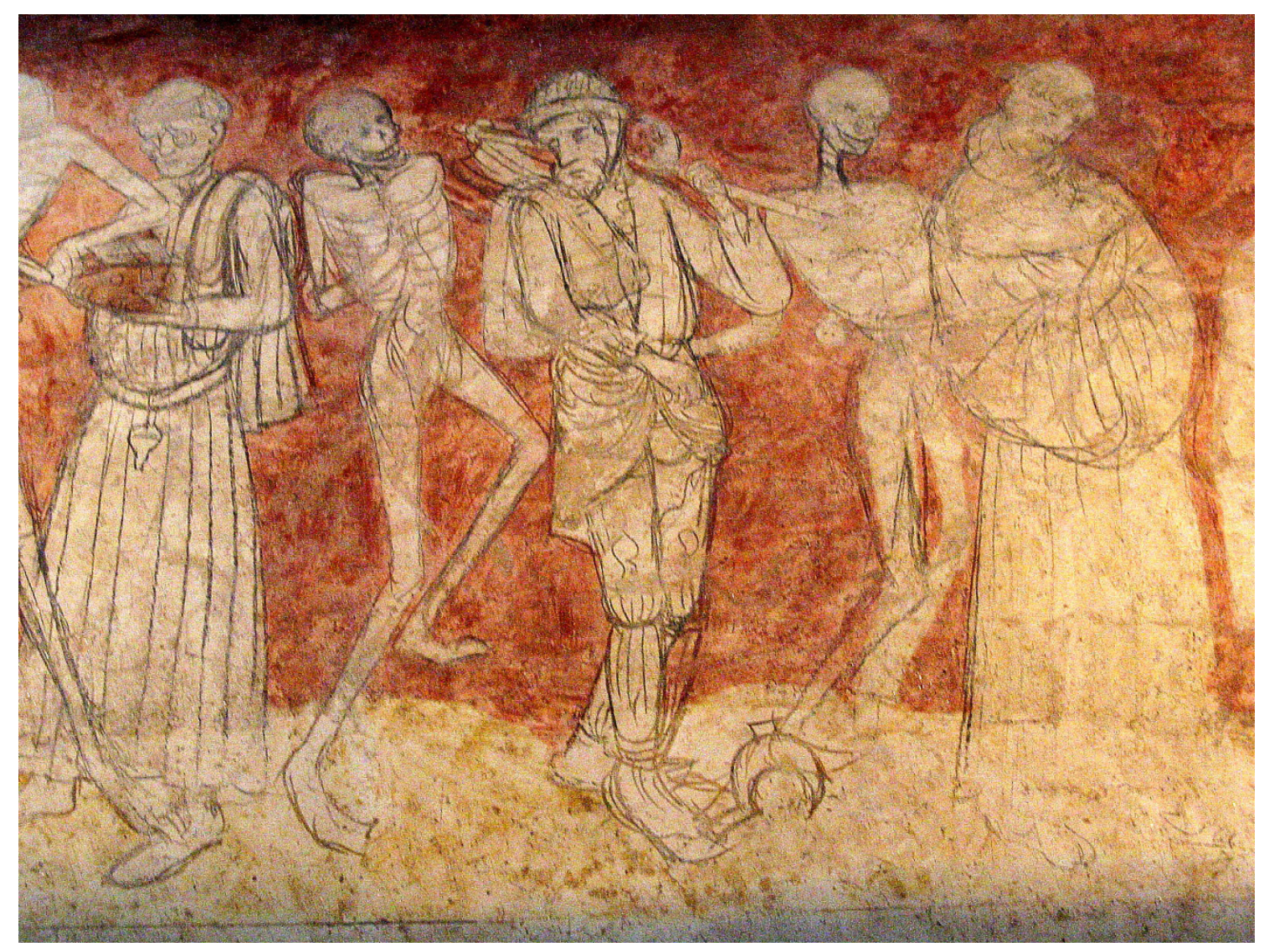

Fuente: imagen extraída de Wikimedia Commons.

así como de los ingresos a las congregaciones marianas y las cofradías de penitentes, o el aumento de las prácticas anticonceptivas rudimentarias arrojan datos contundentes que apuntan hacia un importante movimiento de descristianización del reino (Véase R. Chartier, Espacio público, crítica y desacralización en el siglo XVIII..., pp. 84, 107-126). 
Figura 2: Detalle: el clerc, con sus gruesas lentes, sostiene un misal.

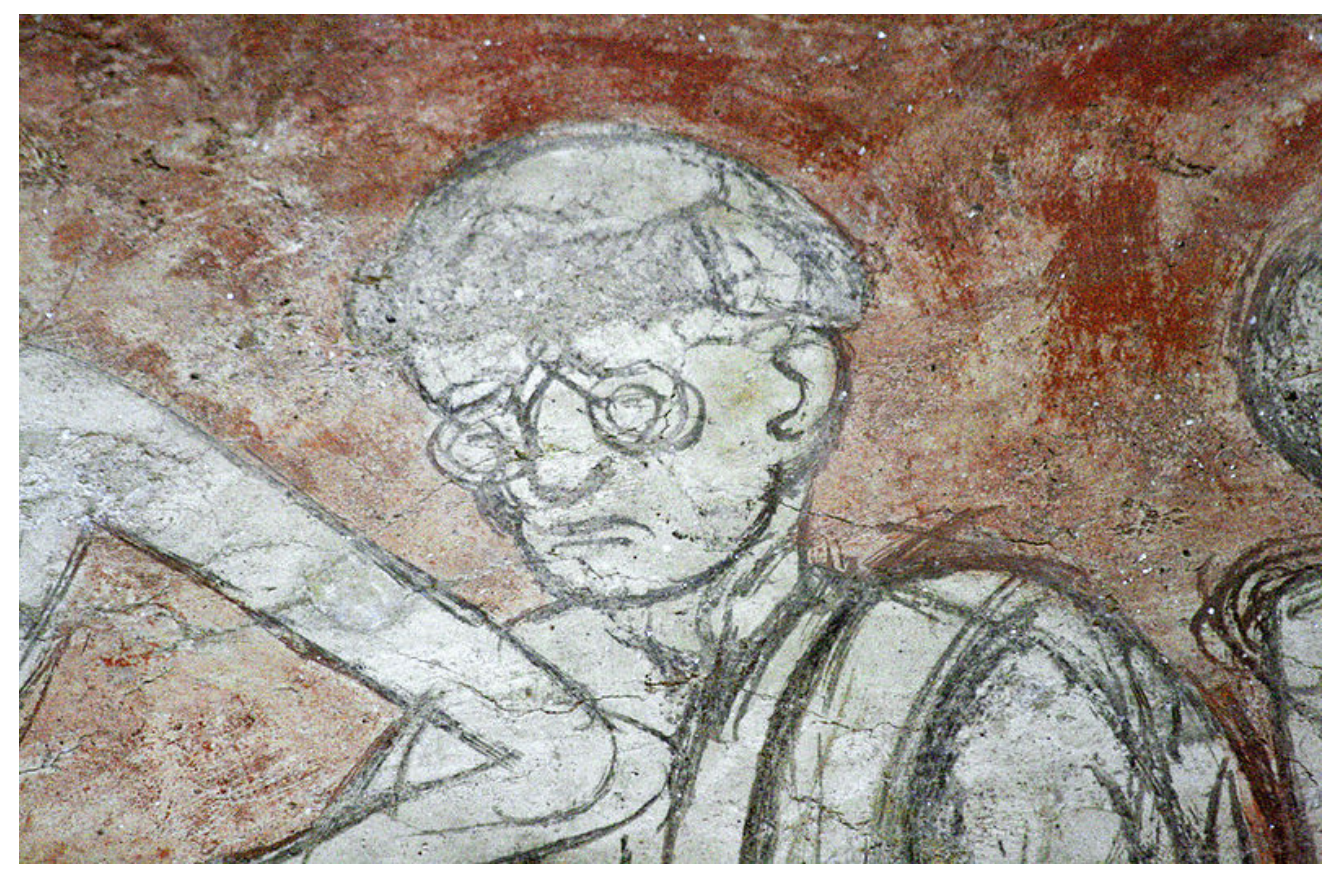


Figura 3. Domenico Fetti, La meditazione, o malinconia, ca. 1618 (Gallerie dell'Academia, Venezia). Este lienzo y La douce mélancolie de Joseph-Marie Vien son mencionados en la entrada "Mélancolie" de la Encyclopédie editada por Diderot y d'Alembert (vol. X, Neuchâtel, chez Samuel Faulche et Compagnie, 1765, pp. 307-311).

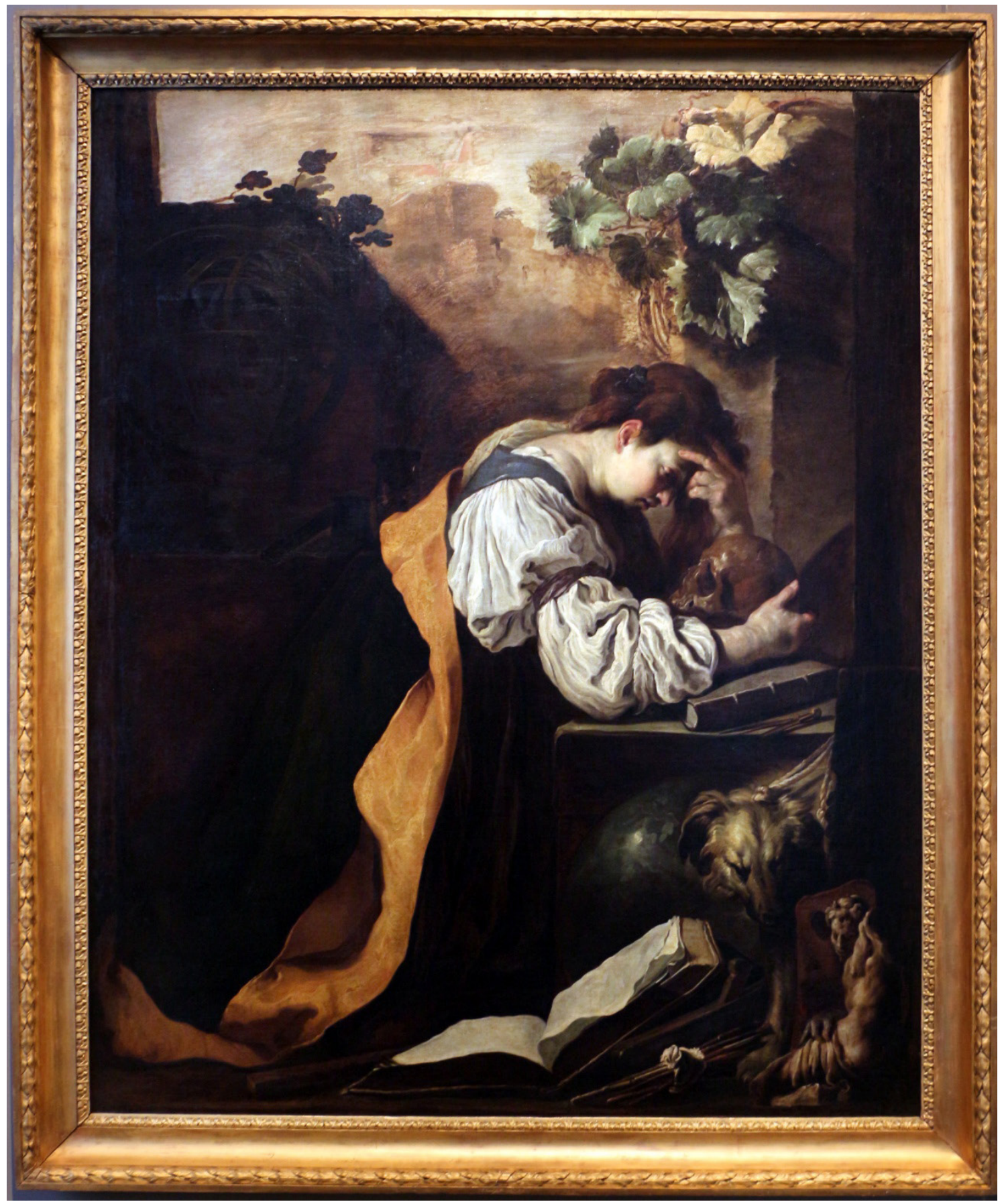

Fuente: Imagen extraída de Wikimedia Commons. 
Figura 4. Albrecht Dürer, Melencolia I, 1514 (Biblioteca Nacional de España, Madrid). Panofsky (op. cit., pp. 334-343) sostiene que el "l" hace referencia a la primera de las tres melancolías que distingue Ernesto Cornelio Agrippa en De occulta philosophia (cuyo manuscrito era conocido desde 1510), la "melancolía imaginativa" (la propia de los artistas y los artesanos), que junto con la "melancolía mentalis" y la "melancolía rationalis" completa la tríada del filósofo neoplatónico alemán.

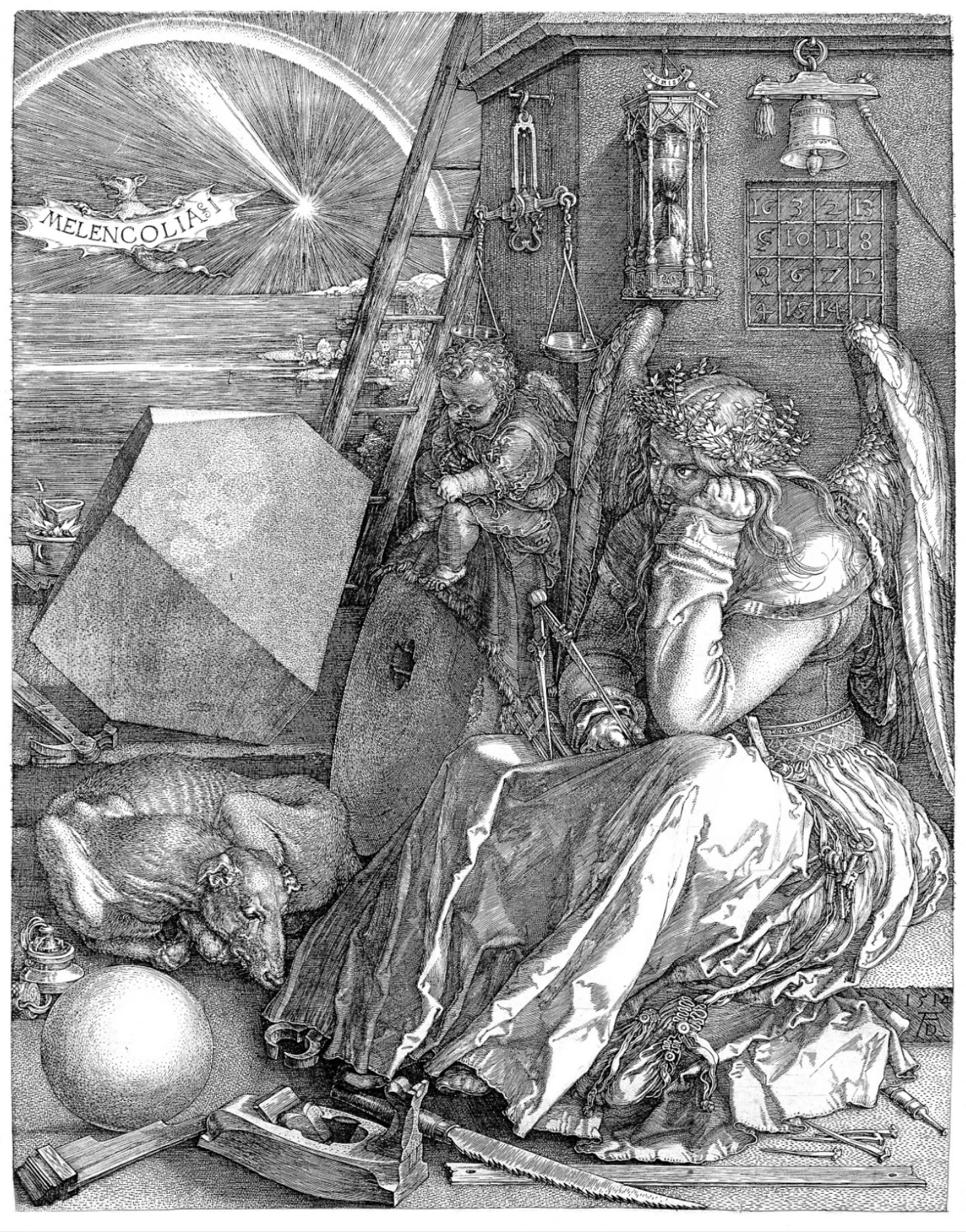

Fuente: Imagen extraída de Wikimedia Commons. 
Figura 5. Joseph-Marie Vien, La douce mélancolie, 1758 (Musée des Augustins, Musée de BeauxArts de Toulouse). El cuadro rompe con algunos de los elementos que encontramos en Dürer y Fetti: la mujer de Vien ya no está rodeada de ruinas o en mitad de un paisaje desértico, sino acomodada en una lujosa alcoba, donde, a pesar de lo que leemos en la entrada "Mélancolie" de la Encyclopédie, no hay libros ni instrumentos musicales dispersos, tan sólo un escrito junto al jarrón de flores sobre la mesa que podría ser una carta de amor. La afable representación de la melancolía parece articularse en torno a este motivo, a la luz del cual cobrarían sentido el ave que descansa en el regazo de la protagonista y el perfume que la envuelve, pues recuerdan los tempranos cultos en los que se ofrecía a Afrodita incienso y palomas sacrificadas.

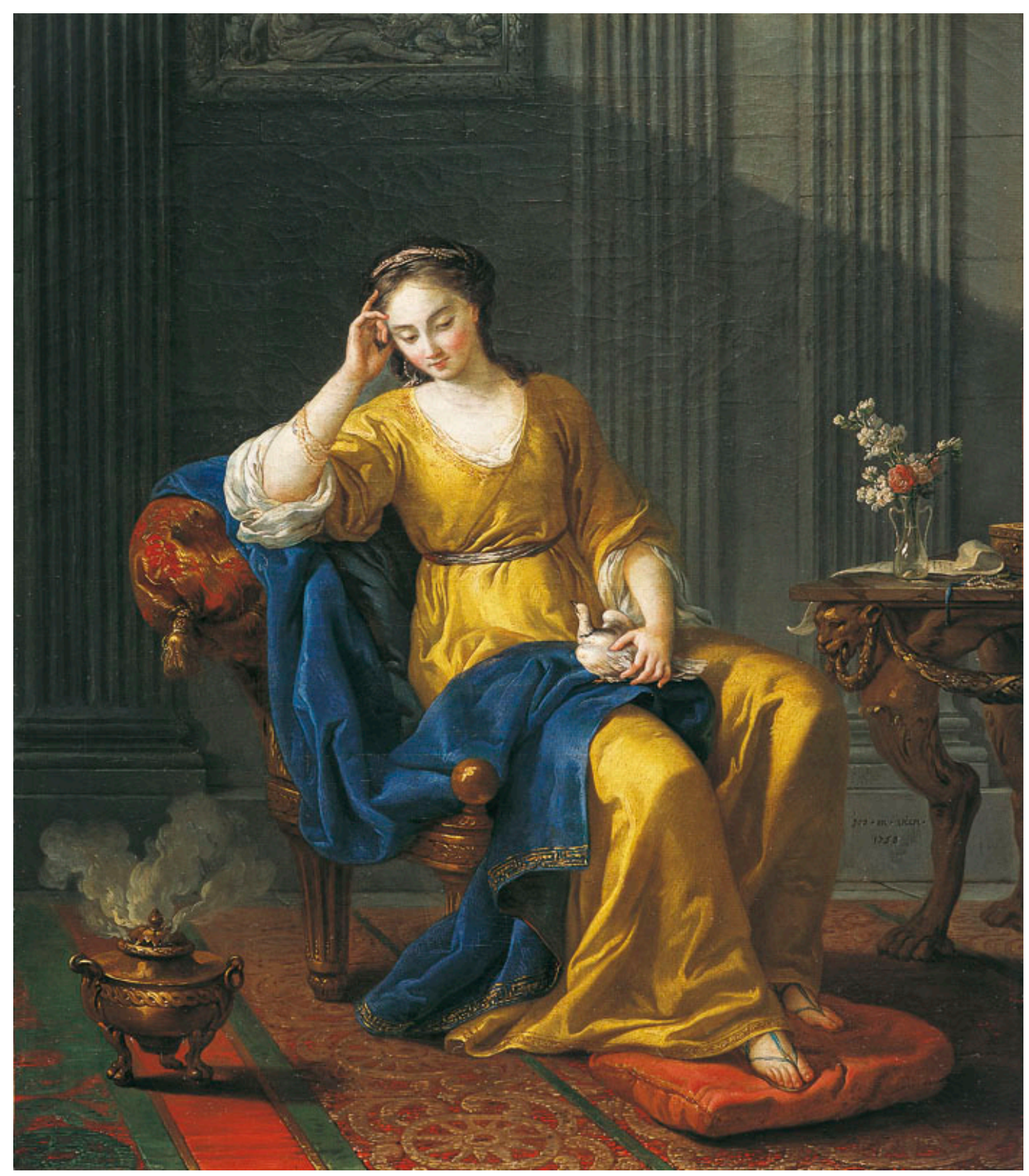

Fuente: Imagen extraída de Wikimedia Commons. 


\section{BIBLIOGRAFÍA}

Agamben, G., Stanze. La parola e il fantasma nella cultura occidentale, Torino, Einaudi, 1977.

Aristóteles, El hombre de genio y la melancolía: problema $X X X$, I, Barcelona, Quaderns Crema, 1996, edición bilingüe, prólogo y notas de Jackie Pigeaud, traducción de Cristina Serna.

Badinter, É., Les passions intellectuelles, vol. I. Désirs de gloire (1735-1751), Paris, Fayard, 1999 (traducción española: Las pasiones intelectuales, vol. I. Deseos de gloria (1735-1751), Buenos Aires, FCE, 2007D'Alembert, "Réflexions sur l'état présent de la République des lettres pour l'article gens de lettres, écrites en 1760 et par conséquent relatives à cette époque", en Euvres et correspondances inédites (éditées par Charles Henry), Genève, Slatkine, 1967.

Bartra, R., Cultura y melancolía. Las enfermedades del alma en la España del Siglo de Oro, Barcelona, Anagrama, 2001.

Bauman, Z., Legisladores e intérpretes. Sobre la modernidad, la posmodernidad y los intelectuales, Buenos Aires, Universidad Nacional de Quilmes, 1997, traducción de Horacio Pons.

Burton, R., Philosophaster, Whitefish, Kessinger Publishing, 1992, ed. Latin-English.

Burton, R., Anatomía de la melancolía, Madrid, Asociación Española de Neuropsiquiatría, 1997-2002, 3 vols., prefacio de Jean Starobinski, traducción de Ana Sáez Hidalgo, Raquel Álvarez Peláez y Cristina Corredor.

Chartier, R., Espacio público, crítica y desacralización en el siglo XVIII. Los orígenes culturales de la Revolución Francesa, Barcelona, Gedisa, 2003, traducción de Beatriz Lonné.

Darnton, R., "La dentadura postiza de George Washington", en El coloquio de los lectores. Ensayos sobre autores, manuscritos, editores y lectores, México, FCE, 2003, prólogo, selección y traducción de Antonio Saborit, pp. 285-310.

Darnton, R., Los best sellers prohibidos en Francia antes de la Revolución, Buenos Aires, FCE, 2008, traducción de Antonio Saborit.

Diderot, D., "Éléments de physiologie", en Fuvres complètes de Diderot revues sur les éditions originales comprenant ce qui a été publié à diverses époques et les manuscrits inédits conservés à la Bibliothèque de lıErmitage, Paris, Garnier frères, 1875-1877, notices, notes, table analytique, étude sur Diderot et le mouvement philosophique au XVIIle siècle par Jules Assézat [et Maurice Tourneaux].

Dumarsais, C. Ch., Nouvelles libertés de penser, Amsterdam, Piget, 1743.

Erasmo de Rotterdam, "Colloquio Ilamado Combite religioso", en A. Herrán y M. Santos (eds.), Coloquios familiares: edición de Alonso Ruiz de Virués (siglo XVI), Rubí (Barcelona), Anthropos, 2005.

Furetière, A., "Hydre", en Dictionnaire universel, contenant généralement tous les mots françois tant vieux que modernes, et les termes de toutes les sciences et des arts..., Paris, France-expansion, 1972 -reproduction de l'édition de La Haye et Rotterdam, A. et R. Leers, 1690, 3 tomes dans un volume, non paginé.

Garin, E., "El filósofo y el mago", en E. Garin (ed.), El hombre del Renacimiento, Madrid, Alianza, 1990, traducción de Manuel Rivero Rodríguez.

Garnier, J.-J., L'Homme de lettres, Paris, Panckoucke, 1764.

Goulemot, J.-M., Adieu les philosophes: que reste-t-il des Lumières?, Paris, Seuil, 2001.

Klibansky, R., Panofsky, E. y Saxl, F., Saturno y la melancolía. Estudios de historia de la filosofía de la naturaleza, la religión y el arte, Madrid, Alianza, 1991, versión española de María Luisa Balseiro. 
Le Goff, J., Los intelectuales en la Edad Media, Barcelona, Gedisa, 1986, traducción de Alberto L. Bixio.

Lepenies, W., ¿Qué es un intelectual europeo? Los intelectuales y la política del espíritu en la historia europea, Barcelona, Galaxia Gutenberg/Círculo de Lectores, 2008, traducción de Sergio Pawlosky.

Masseau, D., L'invention de l'intellectuel dans l'Europe du XVIIle siècle, Paris, Presses Universitaires de France, 1994.

Mornet, D., Les origines intellectuelles de la Révolution française: 1715-1787, Paris, Armand Colin, 1933 (traducción española: Los orígenes intelectuales de la Revolución Francesa, 1715-1787, Buenos Aires, Paidós, 1969, traducción de Carlos A. Fayard).

Radin, P., Primitive Religion. Its Nature and Origin, New York, The Viking Press, 1937.

Rivera García, A., "La pintura de la crisis: Albrecht Dürer y la Reforma", Artificium. Revista iberoamericana de estudios culturales y análisis conceptual, 1 (2010), pp. 100-119.

Schiebinger, L., Nature's body. Gender in the Making of Modern Science, New Brunswick (New Jersey), Rutgers University Press, 2006.

Starobinski, J., "Habla Demócrito. La utopía melancólica de Robert Burton", en R. Burton, Anatomía de la melancolía, vol. I, traducción de Julián Mateo Ballorca, pp. 11-29.

Taine, H.- A., Histoire de la littérature anglaise, Paris, L. Hachette, $2^{\mathrm{e}}$ édition revue et augmentée, 1866.

Tocqueville, A. de, El Antiguo Régimen y la Revolución, Madrid, Istmo, 2004, edición de Antonio Hermosa Andújar.

Van Kley, D. K., The Damiens Affair and the Unraveling of the Ancien Régime, 1750-1770, Princeton, Princeton University Press, 1984.

Vernière, P., "Naissance et statut de l'intelligentsia en France", in Ch. Mervaud et S. Menant (éd.), Le siècle de Voltaire: hommage à René Pomeau, Oxford, Voltaire Foundation, 1987, vol. II, pp. 933-941; É. Walter, "Sur l'intelligentsia des Lumières", Dix-huitième siècle, 5, 1973, pp. 173-201.

Voltaire, Les œuvres complètes de Voltaire / The Complete Works of Voltaire, Genève/Toronto/Paris, Institut et Musée Voltaire/University of Toronto Press, edited by Theodore Besterman], tome 82, Notebooks (vol. 2), 1968.

Weber, M., La ética protestante y el "espíritu" del capitalismo, Madrid, Alianza, 2001, traducción de Joaquín Abellán García. 